\title{
The Rumble in the Bundle
}

\section{Abstract}

In 1952, two well-known characters called ' $A$ ' and ' $B$ ' met for the first time to argue about the Identity of Indiscernibles (Black, 1952). A argued that the principle is true, and $B$ that it is false. By all accounts $A$ took a bit of a beating and came out worst-off. Forty-three years later John O'Leary-Hawthorne offered a response on behalf of $A$ that looked as if it would work so long as $A$ was willing to accept the universal-bundle theory of substance (Hawthorne, 1995). In 1997, $A$ and $B$ met again (Zimmerman, 1997). A took Hawthorne's advice and revealed himself as a universal-bundle theorist. But $B$ was well-prepared, and once more $A$ took a beating. Since then Gonzalo Rodriguez-Pereyra (2004) has put the boot in, offering further criticism of $A$ 's position. In recent years $A$ has been rather quiet, leaving $B$ to reign as the undisputed champion. However, it turns out that $A$ is down, but not out. And now it's time for $A$ 's revenge.

\section{Prologue}

In this prologue I first say a few words about why one might want to hold the universalbundle theory. Then I outline the version of the theory that $A$ wishes to defend in order to defend the Identity of Indiscernibles from $B$ 's attack. I contrast this version with a version of the universal-bundle theory that Rodriguez-Pereyra develops in his (2004) and explain why many universal-bundle theorists may prefer $A$ 's version to RodriguezPereyra's. In the following section I give a brief recap of the previous bouts between $A$ and $B$. By the time I've done this it should be time for $A$ and $B$ to meet once more.

The generic universal-bundle theory is the theory that particulars are entirely constituted by the universals that they instantiate, viz: 
$B T$ : Necessarily, for every particular $\mathrm{x}$ and every universal $\mathrm{y}, \mathrm{y}$ is a constituent of $x$ if and only if $x$ instantiates $y .1$

The theory is developed in terms of immanent universals, i.e. universals that are located wherever and whenever they are instantiated. Bundle theorists are not committed to the view that there is a universal corresponding to every property (i.e. everything that can be predicated of a particular), but they are committed to the view that, as Hawthorne puts it, at the 'metaphysical groundfloor' all that exists are universals (Hawthorne, 1995, p193). They are thus committed to the view that all the properties that a particulars possesses supervene upon the universals it (and perhaps other particulars) instantiate. Most allow that both monadic and polyadic universals (i.e. those that correspond to relational properties) feature in bundles, and this certainly seems to be $A$ 's position. ${ }^{2}$ Thus, we may take $A$ to have a generous conception of universals such that sufficiently many exist to make it true that all of the properties that a particular possesses supervene upon the universals it instantiates.

The universal-bundle theory is an attractive metaphysical view. Nominalism is often lauded by lovers of desert landscapes for its ontological parsimony. Nominalists have particulars at the metaphysical groundfloor and build all other metaphysical categories out of them. Universal-bundle theorists do the same with universals. So the

\footnotetext{
${ }^{1}$ See Rodriguez-Pereyra (2004, p72). Many of the formulations within this paper are based on his. It is worth emphasising here in order to avoid confusion that the constitution relation mentioned in $B T$ is not the material constitution relation that is widely discussed elsewhere in the metaphysical literature. (See Wasserman (2009) for an overview.) The latter relation is the one-one relation that holds, according to some, between persons and their bodies, and between statues and the lumps of clay from which they are formed. By contrast the constitution relation that holds between universals and the particulars they constitute is, like the composition relation, many-one: particulars are plurally constituted by (all and only) the universals that they instantiate.

${ }^{2}$ I take it that this is what lies behind A's desire in 1952 to:

'A: ... include among "properties" what are sometimes called "relational characteristics" - like being married to Caesar or being at a distance from London.' (Black, 1952, p155) Although $A$ here talks of "properties" given his later acceptance of the universal-bundle theory we may suppose that he thinks of these properties as being universals.
} 
universal-bundle theory is just as parsimonious as Nominalism. And by accepting the existence of universals, many will consider the universal-bundle theory to have a distinct advantage over Nominalism. In particular, anyone who agrees with Armstrong that it is a compulsory question in the examination paper to give an account of how two particulars can be of the same type, and who like Armstrong find nominalist accounts wanting, will wish to believe in universals (Armstrong, 1980, pp440-441). The universal-bundle theory also has this advantage over the trope-bundle theory, which must accept that there is a primitive resemblance amongst tropes, or so it seems (Armstrong, 1997, p22-23). Armstrong himself, of course, has developed an account that answers the compulsory examination question by accepting universals. But Armstrong, like many others, sees the need to admit both universals and particulars into his ontology (Armstrong, 1997, pp122-123). But a great many have worries about doing so (e.g. Sellers (1952, 1963), Loux (1978, pp149-152, 2006, p105), Simons (1994, pp565-567), Mertz (2001), Bailey (2012, pp33-35). Given its parsimony, the attraction of accepting universals, and the problems that many see with accepting particulars in addition to universals, the universal-bundle theory will look very attractive indeed to many. Whether it is a defensible position is thus well worth investigating.

In his 2004 Rodriguez-Pereyra recommends, for reasons that will become clear, that the universal-bundle theorist develops the generic version of the theory by maintaining that whenever there is a bundle of universals in a place there is also another entity present, viz. an instance of the bundle. The recommendation is then that particulars are taken as being identical not with bundles of universals but with instances of bundles of universals. Particulars thus instantiate universals by being identical with instances of bundles that contain them. Let us call this the Instance View. In contrast the version that $A$ wishes to defend is the version according to which particulars are 
identical with the bundles of universals that they share their location with. A particular thus instantiates universals simply by being identical with a bundle that contains them. Let us call this the Identity View.

Although the universal constitution relation is not the mereological composition relation, many bundle theorists view it as bearing a very close resemblance to it. The composition relation relates parts to wholes and is supposed by many to be an especially intimate one. A standard view is that a whole is nothing over and above the parts that compose it. Likewise most universal-bundle theorists think that the universal constitution relation is an especially intimate one. Most say that a particular is nothing over and above the universals that constitute it (see Laycock, 2011). What does the 'nothing over and above' locution mean? With regard to composition it is often cashed out by saying that, although the composition relation cannot be identity (because identity is a one-one relation), the relation between a whole and its parts is almost identity. Lewis expresses the point by saying that a whole just is its parts:

The [whole] is nothing over and above the [parts] that compose it. It just is them. They just are it. Take them together or take them separately, the [parts] are the same portion of Reality either way... If you draw up an inventory of Reality according to your scheme of things, it would be double counting to list the [parts] and then also list [the whole]. (Lewis 1991, pp. 81-2)

In just the same way, although the universal constitution relation cannot be identity, many bundle theorists will consider it to be almost identity. A particular just is them. They are just it. In giving an inventory of Reality it would be double counting to list the universals and also list their bundles. 
According to Van Cleve 'sophisticated defenders of the bundle theory do not say that a [particular] is nothing but a bundle of [universals]; they say that it is a bundle whose [constituents] all stand to one another in... the relation co-instantiation.' (Van Cleve, 1985, p97) It is true that sophisticated defenders of the bundle theory do say that whenever we have a bundle of universals, those universals stand in the relation of coinstantiation (also variously called 'compresence', 'togetherness', and 'consubstantiation'). But Van Cleve is wrong in thinking that to say this is to deny that a particular is nothing but its universals. To say this is, in effect, merely to deny that every set of universals forms a bundle (i.e. in the same way that many deny that every set of objects has a fusion). To see this consider: Unless a believer in composition believes in unrestricted composition (i.e. that there is a fusion for every set of objects) she will think that composition only occurs under certain conditions, viz. when the composing objects (i.e. the parts) stand in some sort of relation to one another. Precisely what this relation is, is a moot point - to state it would be to answer van Inwagen's special composition question (van Inwagen, 1990, ch.2). But whatever this relation is, she can call it 'the co-parthood relation' for short. Then she will be committed to the claim that a whole is a fusion whose parts all stand to one another in the relation of coparthood. But she will not thereby be committed to holding that when a whole exists (i.e. when composition does occur) it is something over and above its parts. Likewise, unless a believer in universal constitution believes that universal constitution always occurs (i.e. that there is a bundle for every set of universals) he will think that constitution only occurs under certain conditions, viz. when the constituting universals stand in some sort of relation to one another. Whatever this relation is might also be difficult to state. But whatever it is he can call it 'the co-instantiation relation' for short. Then he will be committed to the claim that a particular is a bundle whose constituents 
all stand to one another in the relation of co-instantiation. But he will not thereby be committed to holding that when a bundle does exist (i.e. when constitution does occur) it is something over and above its constituents. There are no doubt other problems with cashing out precisely what the co-instantiation relation is, but invoking it does not prevent the universal-bundle theorist from claiming that a bundle of universals is nothing over and above its constituents.

A commitment to the idea that the mereological composition relation is an especially intimate one gives rise to a commitment to the following principle:

Parts: Necessarily, for all composite objects $\mathrm{x}$ and $\mathrm{y}$, and every object $\mathrm{z}$, if $\mathrm{z}$ is $\mathrm{a}$ (proper) part of $\mathrm{x}$ if and only if $\mathrm{z}$ is a (proper) part of $\mathrm{y}$, then $\mathrm{x}$ is numerically identical with $y$.

Many do deny Parts and believe that distinct objects can share all of their parts. Indeed, the denial of Parts is a basic commitment in what was once correctly called the 'standard account' of material objects, although the 'standard account' has now fallen out of favour for a number of reasons. ${ }^{3}$ Aside from being objectionable because it breaks the intimate connection between a whole and its parts, there are other serious objections to it. The one considered to be the most serious (indeed, it is considered decisive by some), is the so-called grounding objection. When two distinct objects share all of their parts they share all of their categorical properties too (e.g. they have the same size, weight, shape, etc.). Yet according to the standard account they can differ with respect to their non-categorical properties (e.g. their temporal properties, their

\footnotetext{
${ }^{3}$ The view in question was dubbed 'the standard account' by Burke (1992) and is still known by this name despite now being out of favour (See Wasserman (2002)). Burke gives a list of eleven philosophers who have defended the view in print (ibid. p13).
} 
modal properties, etc.). The grounding objection is simply that the defender of the standard account cannot account for these differences. "What grounds these differences?" asks the objector, "'How can two things that are exactly alike in so many ways still differ in these other respects?"” (Wasserman, 2009). ${ }^{4}$

The relevance of this to the present issue is this: just as a commitment to the idea that the composition relation is an especially intimate one gives rise to a commitment to Parts, a commitment to the idea that the universal constitution relation is an especially intimate one gives rise to a commitment to an analogous principle for the universal-bundle theorist, viz:

Constitutents: Necessarily, for all particulars $\mathrm{x}$ and $\mathrm{y}$, every universal $\mathrm{z}$, if $\mathrm{z}$ is a constitutent of $\mathrm{x}$ if and only if $\mathrm{z}$ is a constitutent of $\mathrm{y}$, then $\mathrm{x}$ is numerically identical with $y$.

But $B T$ together with Constituents entails the following principle:

UII: Necessarily, for all particulars $\mathrm{x}$ and $\mathrm{y}$, and every universal $\mathrm{z}$, if $\mathrm{z}$ is instantiated by $\mathrm{x}$ iff $\mathrm{z}$ is instantiated by $\mathrm{y}$, then $\mathrm{x}$ is numerically identical with $\mathrm{y}^{5}$

Because on a view like $A$ 's where all properties that a particular possesses are supposed to supervene upon the universals that the particular instantiates, UII in turn entails the

\footnotetext{
${ }^{4}$ Although Wasserman (2009) states the grounding objection in this way, i.e. in terms of categorical and non-categorical properties, some object to this way of putting it and instead suggest it should be framed by asking how objects that share all their categorical non-sortal properties can differ in their sortal properties (e.g. Mackie (2008, p168)). I agree with this point, but nothing that I say depends upon my taking this complication into account, so for the sake of this paper I ignore it.

${ }^{5}$ Again, see Rodriguez-Pereyra (2004, pp76-77) on this.
} 
more general $I I$ :

$I I$ : Necessarily, for all particulars $\mathrm{x}$ and $\mathrm{y}$, and every property $\mathrm{F}$, and all times $\mathrm{t}$, if Fx at $t$ if and only if Fy at $t$, then $x$ is numerically identical with $y$.

This is (a version of) the principle of the Identity of Indiscernibles and it is a commitment to this principle (as we will see) that has caused all the trouble for universal-bundle theorists. Thus, one way for the universal-bundle theorist to avoid trouble here is by avoiding a commitment to UII. And the universal-bundle theorist can avoid a commitment to UII by avoiding a commitment to Constituents. It is precisely this that Rodriguez-Pereyra recommends by outlining the Instance View. The Instance View is analogous to the 'standard account' of material objects. On the Instance View instances of bundles, unlike bundles themselves, cannot be located in more than one place. Thus where we have a single multiply located bundle of universals we have multiple distinct instances of that bundle. Because on the Instance View ordinary particulars are instances of bundles rather than bundles themselves, he thus recommends that the universal-bundle theorist accepts that two distinct particulars can instantiate the very same universals. They thus deny Constituents, and so avoid a commitment to $U I I$ and $I I$.

$A$, of course, cannot take Rodriguez-Pereyra's recommendation and accept the Instance View. This is because $A$ accepts the universal-bundle theory in order to defend II. So $A$ is committed to the Identity View. But why might universal-bundle theorists who lack such an ardent commitment to $I I$ wish to accept the Identity View over the Instance View? One simple reason is that it is the more natural version of the bundletheory. Rodriguez-Pereyra's motivation for developing the Instance View was to 
provide a version of the universal-bundle theory that is not committed to $I I$, since he thinks that the commitment to $I I$ is unacceptable. But if $A$ manages to defend the acceptability of the Identity View's commitment to $I I$, this motivation is undercut. Two further reasons derive from the parallel that holds between the Instance View and the 'standard view' of material objects. Firstly, the Instance View might be seen to be objectionable on the grounds that it breaks the intimate connection between a particular and its constituent universals. Secondly, it seems that the Instance View is open to an analogous grounding objection. On the Instance View bundles of universals and their instances differ in their non-categorical properties. Consider a multiply located bundle of universals Bun and one of its instances Ins. Bun has the property of existing at more than one place, but Ins does not. But Bun and Ins are by hypothesis constituted by exactly the same universals. So how can they differ in their properties in this way? What is it that grounds this difference between Bun and Ins? In fact, this version of the grounding objection is particularly pressing for universal-bundle theorists like $A$ because, as we have seen, on their view all the properties of a particular are supposed to supervene upon the universals it instantiates. Given that Bun and Ins instantiate all and only the same universals, how can Ins possess any property that Bun does not, or vice versa? ${ }^{6}$

I do not claim that the grounding objection to the Instance View is decisive, but I suspect many will think that it is, and so will wish to reject the Instance View in favour of the Identity View for this reason alone. Moreover, whether or not the grounding objection is decisive, I suspect that many universal-bundle theorists will nevertheless

\footnotetext{
${ }^{6}$ Rodriguez-Pereyra also suggests that even when bundles are not multiply located they have instances (2004, p78). In such a case the instance and the bundle will still differ in their properties. The bundle will have, and the instance will lack, the de re modal property of possibly existing at more than one place. But, so the grounding objection goes, by hypothesis they are constituted by exactly the same universals. So how can they differ in their de re modal properties?
} 
wish to accept the Identity View on account of its being the more natural position that maintains the intimate connection between a particular and its constituent universals. For any universal-bundle theorist who does wish to accept the Identity View, whether $A$ can defend the view against $B$ 's attack will be of the utmost concern.

\section{The Story So Far}

Max Black records the first meeting between $A$ and $B$ in his well-known paper 'The Identity of Indiscernibles'. In that meeting $A$ attempts to defend $I I$, and $B$ attacks it. Although $A$ does land some glancing blows, $A$ gets a bit of a thrashing from $B$, who offers the following well-known thought experiment that purports to show that $I I$ is false:

$B$ : Isn't it logically possible that the universe should have contained nothing but two exactly similar spheres? We might suppose that each was made of chemically pure iron, had a diameter of one mile, that they had the same temperature, colour, and so on, and that nothing else existed. Then every quality and relational characteristic of the one would also be a property of the other. Now if what I am describing is logically possible, it is not impossible for two things to have all their properties in common. (Black, 1952, p156)

In effect, using the above description to tempt him, $B$ invites $A$ to agree that the following statement is true:

$B U$ : Possibly, there exist two objects that share all of their properties. 
If $B U$ is true $I I$ is false. Given the possibility that $B$ describes does indeed look to be a possibility, $B$ 's description really is tempting and $B$ gains the upper hand. $A$ 's response to $B$ after this blow is delivered is feeble; $A$ ends up denying that the possibility $B$ describes is a possibility at all (ibid. p163). So the meeting ends with $A$ on the ropes looking distinctly 'modally-challenged'.

$A$ need not have ended up looking modally challenged. $A$ need not have denied that the possibility $B$ describes is a possibility. $A$ could instead have denied that $B$ 's description of the possibility was correct. But in order to do this, $A$ would have had to adopt the Identity View described above. This is what Hawthorne makes clear in his (1995). The idea is this: Because the Identity View entails $I I, B$ 's argument is just as threatening to this position as to A's. But universals, by definition, are things that can exist wholly and completely at some distance from themselves, and so the defender of the Identity View ought to think that bundles of them can also exist wholly and completely at some distance from themselves too. So, the defender of the Identity View ought to reject $B$ 's description of the possibility, and insist that it is correctly described as being the possibility that a single bundle of universals is located at a distance from itself. If $B$ insists that his description $i s$ the correct description of the possibility, then $B$ simply begs the question against the Identity View. So, if $A$ had adopted the Identity View, and given this response, $A$ could have regained the lost ground without appearing to be modally-challenged. ${ }^{7}$

The story continues. In his (1997) Dean Zimmerman records the second meeting between $A$ and $B$. $A$ has now read Hawthorne's article, takes his advice, and it is revealed at the start of the meeting that $A$ is a proponent of the Identity View. $A$ starts

\footnotetext{
${ }^{7}$ Of course, there may well be something wrong with the very idea that something can be located at a distance from itself, but if there is then there's something wrong with the very concept of a universal, and nothing that $B$ says does anything at all to show that this is so (See Hawthorne (1995)).
} 
well giving an outline of the above response to $B$ 's previous attack. But $B$ is prepared for this and has a counter-response to hand (perhaps $B$ too has read Hawthorne and has the counter-response pre-prepared). Being a little more cautious in describing possibilities, $B$ says:

B: Suppose that nothing exists save... the same bundle of electronish properties on opposite sides of a symmetrical universe. Suppose further that electrons obey indeterministic laws. In that case even though the electron on the one side is now indiscernible from the one on the other, it remains possible that the differences will emerge later on - in other words, it is possible that this one should have a future differing from that one. And even in the case of an eternally symmetrical, two-electron universe in which differences never emerge, such differences were nonetheless possible - both logically or metaphysically possible, and physically or causally possible, too. But you cannot recognize this possibility: on your view the "electrons" must really be a single bundle, and so nothing could be true of the one but false of the other. (Zimmerman, 1997, pp306-307)

Initially it looks as if $A$ is not going to let $B$ gain the upper hand once more. $A$ invokes a counterpart-theoretic approach to de re modality thus:

A: According to my counterpart semantics, the possibilities open to a given object are not determined by what it does in other possible worlds, but rather by what its counterparts do in other possible words - and a counterpart is similar to, but not identical with, the original object. I can simply adopt a semantics for 
the statement "The (so-called) 'two' electrons could have diverged" that ascribes truth to this statement just in case the single bi-located electron-bundle in the world you described has two counterparts inhabiting some other world, and the counterparts differ in the required ways. (ibid. p307)

But alas, $B$ is ready once more:

$B$ : [E]ven if I grant you [counterpart semantics for modal ascriptions], I don't see how it helps. The world you describe, in which the bi-located bundle has two counterparts, allows you to say that the one bi-located electron could have been two electrons. But something more is possible in the world I described: the electron on one side could have developed differently while the one on the other side did not. But if "they" are identical, "they" must have the same counterparts in every possible situation - and so there's no possible world in which the one but not the other has a counterpart with a particular future. (ibid. p307)

After this, $A$ fades as before. $A$ accepts $B$ 's response and resorts again to simply denying that the possibility that $B$ describes is a possibility at all. So the meeting ends with $A$ back on the ropes looking modally-challenged once more. But again, $A$ need not have ended up looking like this. A should have persisted with the counterpart-theoretic response. In fact, doing so would not only have allowed $A$ to respond to $B$, but $A$ would also have then been in a position to respond to a number of further criticisms that Rodriguez-Pereyra presses in his (2004). But look, I won’t say any more about it now, as $A$ is going to talk about it in his next meeting with $B$, which is happening right now. 


\section{The Revenge}

A: Last time we met you described the possibility of a universe containing nothing but a bundle of electronish universals located wholly and completely on either side of a symmetrical universe. You supposed that this bi-located electron could follow indeterministic laws such that the bundle on one side of the universe might have developed differently from the bundle on the other, even though it does not actually develop differently.

B: Quite so. I remember it well. You ended up denying that this was a possibility!

A: Well, I was young(ish) and foolish. But just as I should never have denied that the sphere universe was possible the first time we met, I should not have denied that the electron universe you described was possible either. I should just have denied that your description of it was correct.

B: That's fine. You're entitled to change your opinion. But I presume you haven't changed your opinion about the truth of the universal-bundle theory (which I now hear you are calling 'the Identity View'), so how do you now propose to describe the possibility that one of the electrons on one side could have developed differently from the one on the other?

A: First off, I don't think that "one" of them could have developed differently from "the other" because I think that there is only one electron in the possibility you describe. I would rather say that the bi-located electron could have developed in a different way from itself on one side of the universe to the other.

$B$ : That sounds very odd to me...

A: Lots of things people say in metaphysics sound odd. It's part of my position that some entities can be wholly located in more than one place at the same time. That no doubt sounds odd to you too. But that's not much of an objection. At any rate, 
given that I think that there is only one electron in the world we're considering, how else would you like me to describe the possibility?

$B$ : I don't know, but perhaps there's a reason why this sounds odd. If the electron had developed in a different way from itself then it would have been non-identical with itself. Isn't this contradictory?

A: Not quite. Then the electron would have been two things rather than one. But you've already allowed that I can say this by using a counterpart-theoretic account of de re modality. ${ }^{8}$

$B$ : Oh, counterpart theory again! Well, OK then, I suppose I do have to grant you the above description of the possibility. But now I want to know a little more about how counterpart theory allows you to say that the bi-located electron could have developed in a different way from itself. I can't quite see how it does allow you to say this. The point I made before still stands. According to counterpart theory the $d e$ re modal properties that an object has are determined by what its counterparts do in other possible worlds. But as the "two" electrons are really just one according to you, it has the same counterparts in every possible situation, and so there's no possible world in which it-on-one-side of the universe has a counterpart that does one thing and it-on-the-other-side has a counterpart that does another.

A: Maybe there's something in what you say here, but I don't think that you've put whatever it is in the right way. Your claim appears to be that because I think that there is only one electron here I must say that it has the same counterparts in every possible situation and that it is this that causes me a problem here. Is that right?

$B$ : That's what I said.

${ }^{8} \mathrm{Cf}$. Lewis on the idea that 'an identity pair might have been a non-identity pair (or vice versa)' (Lewis, 1986, p259). For more on counterpart semantics see also Lewis (1968) and Lewis (1971). 
A: But this can't be quite right. I became suspicious of this claim when I noticed that, if the possibility you describe is a problem for me, then it is a problem for all counterpart theorists who think that the counterpart relation is a relation of similarity (like David Lewis, for example). ${ }^{9}$ It is not the fact that there is a single electron here that causes the supposed problem, but the fact that the electrons are indistinguishable. If you're right then even a counterpart theorist who thinks that there are two indistinguishable electrons in the example cannot allow that there is a world in which one of them has a counterpart that does one thing and one of them has a counterpart that does another. This is for the simple reason that anything that bears a resemblance to one of the electrons will, by hypothesis, bear the same resemblance to the other. So, if you're right, it's not just me who can't allow for the possibility you describe, but any counterpart theorist who thinks the counterpart relation is a relation of similarity. So, if your argument is conclusive against my view it's conclusive against counterpart theory in general.

$B$ : OK, so my objection to your account is a general objection to this type of counterpart theory too. So much the worse for counterpart theory I say!

A: Except I'm not so sure your objection works. Let's suppose the possibility you're envisaging is one in which the-electron-on-one-side swerves off to the left whilst the-electron-on-the-other does not. You seem to think that I need there to be a world in which the-electron-on-one-side has a counterpart that swerves off to the left whilst the-electron-on-the-other does not. Is this right?

$B$ : Yes. To be clear what you require is that in some single world it-on-one-side has a counterpart that swerves off whilst it-on-the-other does not. And it is this that you cannot have. Indeed, even if you could have it, you would then be committed to

\footnotetext{
${ }^{9}$ See (ibid., p254).
} 
saying that the electron could have swerved off and not swerved off, and that's a contradiction!

A: That last point is certainly not right. There is sense in which the electron could have swerved off and not swerved off. But this just means that it has a counterpart that swerves off and a counterpart that does not, and this is not contradictory. What would be contradictory is if the electron had a counterpart that both swerves off and does not swerve off, but of course it has no such counterpart.

$B$ : OK, I retract the last point. But the first one still stands. You need, but cannot have it that, the-electron-on-one-side has a counterpart that swerves off whilst theelectron-on-the-other does not.

A: But I don't need this. Indeed, if I did have this then there really would be two electrons in the original example, because one would have different modal properties to the other.

$B$ : I don't follow what you mean.

A: Perhaps if I ask you a question it will help. You think that there really are two electrons in the example. And you say that one of them could have developed differently from the other. By this do you mean to say that one of them has a modal property that the other does not? If so, which one?

$B$ : Well, no. Of course the electrons must have the same modal properties, otherwise they'd be distinguishable after all, and we're supposing that they're indistinguishable.

A: Right. So a fortiori the bi-located electron must have the same modal properties on both sides of the universe, so it cannot be that I require there to be a world where the-electron-on-one side has a counterpart that swerves off and the-electron-on-the- 
other does not, because on my account this would be for there to be two electrons after all.

$B$ : So what is it that you do require?

A: Simply that there is a single world in which the electron has one counterpart that does swerve off and one counterpart that does not. And there is such a world. The bi-located electron in our example obeys indeterministic laws. So, in an otherwise identical world (call it $\mathrm{w}_{\mathrm{N}}$ ) in which one electron does swerve off and one remains moving forward, the two electrons would be equally similar in all relevant respects to the bi-located one in our original world (call it wo) So, they would be tied for eligibility for being counterparts of it, and so both would be counterparts of it. ${ }^{10}$ And that's it. The bi-located electron in wo could have developed in a different way from itself. It could have been two things. One of the things it could have been is a thing that swerves off to the left and one of the things it could have been is a thing that remains moving forward. This is all that I require, and I do indeed have this. So I can easily recognise the possibility you describe.

$B$ : Hang on. I don't see how this can work. To make things easier let's call the original bi-located electron from wo "Bilo", let's call the electron the swerves off in $w_{N}$ "Swerve" and let's call the electron that does not swerve off in $\mathrm{w}_{\mathrm{N}}$ "Steady". You say that both Swerve and Steady would be counterparts of Bilo, but how can this be? Because Bilo doesn't swerve off in wo, isn't Steady (in virtue of being the electron that doesn't swerve off in wN) more similar to Bilo than Swerve? And if so, isn't it the case that, in fact, Steady is the (one and only) counterpart of Bilo in $\mathrm{wn}_{\mathrm{N}}$ ? That is, because Steady is more similar to Bilo than Swerve, isn't it the case that Swerve doesn't count as being a counterpart of Bilo at all?

\footnotetext{
${ }^{10}$ See (Lewis, 1986, p258).
} 
A: No. This is to misunderstand how counterpart theory works. I don't have to establish that both Swerve and Steady are genuine counterparts of Bilo before I can claim that that the possibility you describe is a genuine possibility. Rather, the fact that the possibility you describe is a genuine possibility for Bilo shows that both Swerve and Steady are genuine counterparts. That is, because Bilo really could have swerved off on one-side of the universe and not the other, it must be that the Swerve and Steady are equally similar in all relevant respects to Bilo.

$B$ : What do you mean by "in all relevant respects"? These seem like weasel words to me!

A: I promise you they are not. Let me explain. Some differences in similarities between individuals are not relevant to the assessment of whether those individuals are counterparts of other-worldly objects. This is often the case, for example, with relational differences (and I think it's sometimes the case for intrinsic differences too, although I won't press this point here). For example, consider a world containing two intrinsically alike duplicates of you, with the only difference between them being that one has a different relational property to the other, say, that one has some gum stuck to the bottom of his shoe and the other does not. Now suppose that they are matched in all respects of similarity to you except in the respect of the gum. Because you actually have gum stuck to your shoe, the former is more similar to you than the latter. It is clear, I think, that it would be gratuitous to say the latter could not be a counterpart of you because of this. The two duplicates of you are intrinsically exactly alike, and the small relational difference in similarity would not normally be a relevant difference. So it is independently plausible that both will be counterparts of you in most ordinary contexts, even though one is more similar in some respects than the other. Now consider Swerve and Steady again. They too are 
intrinsically exactly alike, we are supposing, and the only difference between them is a relational difference - they take slightly different trajectories from each other. So, just as it is gratuitous to say that the duplicate of you that does not have gum on his shoe could not be a counterpart of you because he does not have gum on his shoe whilst the other duplicate does, it is likewise gratuitous to say that Swerve could not be a counterpart of Bilo because it swerves off whilst Steady does not. So, it is independently plausible that both Swerve and Steady will be counterparts of Bilo in most ordinary contexts, even though Steady is more similar to Bilo in some respects than Swerve. Do you see?

$B$ : I think so... You think that, because the difference in similarity that makes Steady more similar to Bilo than Swerve, is not a relevant difference, this gives us reason to think that both Steady and Swerve are counterparts of Bilo. Is that right?

A: Not quite. This makes it sound as though what I've just said is supposed to be an argument for the claim that Swerve and Steady are both counterparts of Bilo. But it is not supposed to be an argument for this claim. I just wanted to make it clear here, in an intuitive sense, why it is that even though an object within a world is more similar than another to an object in another world, this does not mean that both cannot be counterparts of that other object. But as I said, that both Swerve and Steady are genuine counterparts of the Bilo is established by the fact that it is a genuinely possibility for Bilo that it could have swerved off on one side of the universe and not the other in wo.

B: Well, OK. Now I see. But I still find the idea that one thing could have been two things very strange. I just think it's obvious that there are two electrons and not one in the original example I described above. 
A: Some argument! I think the Identity of Indiscernibles is obviously true. So we're at a stalemate. I can recognise all of the possibilities that you can and so you've done nothing at all to show that my view is false.

$B$ : But you can't recognise all the possibilities I can, because I can recognise the possibility of there being a world with two indistinguishable black spheres in it, and you can't.

$A$ : Oh we're back to this again are we. You're still missing the point. I $d o$ recognise this possibility, but I think you misdescribe it when you describe it as a world with two spheres in it. If you insist on sticking to this description, then I say flatly that it is not a possibility at all.

$B$ : But it's just this denial that makes you modally challenged.

A: Again, I must demur. How can I get through to you? Perhaps an analogy will help. Forget for a moment that I am a counterpart theorist and suppose that I recognise the possibility that I could have been born of different parents, i.e., that I could have been born from a different sperm and egg. Do you recognise this possibility?

$B$ : No I certainly do not! I'm convinced that there is no such possibility by Kripke's argument for the necessity of origin. ${ }^{11}$

A: Of course, that's another failing of yours, but I'll let it pass. The point is that I can very easily give a description of a world which is just like this one, in which someone just like me exists. This person who is just like me looks like me, walks like me, talks like me, and so on, and has done all the things that I have done. Indeed, the only difference between this person and me is that he has been born of different parents. Now, suppose I claim that this person in fact is me, and the possibility I am

\footnotetext{
${ }^{11}$ See (Kripke, 1980, fn. 56).
} 
describing is the possibility of me being born of different parents. What would you say?

$B$ : I see where this is going...

A: Let me continue for you. You would say that I had misdescribed the possibility by giving this extra piece of information. Of course, you can still recognise the possibility that I describe, but you would not describe it as a possibility in which I was born of different parents. You would describe it as a possibility in which someone just like me is born of different parents. Would this make you modally challenged?

$B$ : You're putting words in my mouth now, but I do take the point. No, it would not make me modally challenged. And so likewise, you are right, I cannot say that you are modally challenged by denying that the world I describe as containing two black spheres is a world with two black spheres. But anyway, this now strikes me as beside the point, for I have an argument that the possibility that I describe, as I describe it, is a real possibility.

$A$ : I'd love to hear it.

$B$ : OK. Here it is: '[T]here is a possible world like [the original black sphere world] except that the spheres differ infinitesimally in temperature. No one should deny the possibility of such worlds, and certainly there is nothing in them that a bundle theorist [like you] cannot accept. That world contains two particular spheres, $a$ and $b$. But if $a$ has a temperature T and a different particular $b$ of the same kind as $a$ has a temperature $\mathrm{T}^{*}$ infinitesimally different from $\mathrm{T}$, then it is possible for $a$ to have $\mathrm{T}^{*}$. Thus if the world with the almost indiscernible spheres is possible, so is another 
world in which the spheres are completely indiscernible. So [the original] world, which contains two indiscernible particulars, is possible.' 12

A: The new world that you're describing is a world with two different bundles of universals so, of course, you are right that I think that there are two spheres in the new world. But it should be obvious that the argument you give is ineffective, for I think that the infinitesimal difference between this new world and the original world does make all the difference. My position is entirely analogous to the perdurantist's. Consider a world in which an amoeba survives for a long time without dividing and then goes out of existence. For the perdurantist this is a world in which there is only one amoeba. Now consider another world where an exactly similar amoeba survives for a long time, but divides an infinitesimal length of time before (both resulting amoebas) go out of existence. For the perdurantist this is a world in which there are two amoebas that overlap throughout most of their existence and then exist separately for an infinitesimal length of time. The fact that perdurantists will admit that there are two amoebas in the second world gives them no reason to think that there are two in the first world. Likewise, the fact that I admit that there are two spheres in the new world you describe gives me no reason to think that there are two in the original world! So again, I say, we're at a stalemate. I can recognise all of the possibilities that you can and you've done nothing at all to show that my view is false.

$B$ : So you $d o$ admit, then, that if I can show that there is an obvious possibility that you cannot recognise that I can, then I will have done enough to show that your view is false?

\footnotetext{
${ }^{12}$ Here B is just quoting (almost) verbatim from Rodriguez-Pereyra (2004, p74). This sort of argument has something of a pedigree and can be traced back to Adams (1979: 17-19).
} 
A: Of course. I've always been willing to admit this. It's just that nothing you've said does show this.

B: OK. I am willing to admit that so far I have not succeeded in showing this. But now I think I have you, for there is one last argument that I am certain does succeed in showing that there are obvious possibilities that you cannot recognise but that I can. Here it is: Consider 'a world W with just a single bundle located in two places two miles apart from each other, and a world $\mathrm{W}^{*}$ with the same bundle located in three places every two of which are two miles apart from each other (thus the bundle forms an equilateral triangle). ${ }^{, 13}$ Clearly these two worlds are possible and represent distinct possibilities. I can easily distinguish them: one is a world with two spheres, and one is a world with three. But how can you distinguish them? I submit that you cannot.

A: Really? Why can I not just distinguish them by saying that one is a world in which there is a bi-located sphere and one is a world in which there is a tri-located sphere?

$B$ : Because this is just to say that in the first world the sphere stands in a dyadic relation to itself and in the second it stands in a triadic relation to itself, but this can't help you to distinguish the worlds. The dyadic relation in the world where the bundle is bi-located is a relation $\mathrm{R}$ that obtains between $\mathrm{x}$ and $\mathrm{y}$ if and only $\mathrm{x}$ and $\mathrm{y}$ are two miles apart. But this relation R also obtains between the bundle and itself in the world where the bundle is tri-located. For there it is also the case that there is an $\mathrm{x}$ and $\mathrm{y}$ such that $\mathrm{x}$ and $\mathrm{y}$ are two miles apart. Similarly, 'the triadic relation in the world where the bundle is tri-located is a relation $\mathrm{R}$ that obtains between $\mathrm{x}, \mathrm{y}$ and $\mathrm{z}$ if and only if $\mathrm{x}$ and $\mathrm{y}$ are two miles apart, $\mathrm{y}$ and $\mathrm{z}$ are two miles apart, and $\mathrm{x}$ and $\mathrm{z}$ are two miles apart. But this relation $\mathrm{R}$ also obtains between the bundle and itself in the world

\footnotetext{
${ }^{13}$ Again, $B$ is quoting from Rodriguez-Pereyra (2004, p75).
} 
where the bundle is bi-located. For there it is also the case that there is an $\mathrm{x}, \mathrm{y}$ and $\mathrm{z}$ such that $\mathrm{x}$ and $\mathrm{y}$ are two miles apart, $\mathrm{y}$ and $\mathrm{z}$ are two miles apart, and $\mathrm{x}$ and $\mathrm{z}$ are two miles apart. ${ }^{14}$

$A$ : Yes, you are right about this, I cannot distinguish between the worlds in terms of a dyadic relation holding between the sphere and itself in one world and a triadic relation holding between it and itself in the other. But I don't see why this should bother me, because there is another way for me to distinguish between the worlds that does perfectly well.

$B$ : Now I'd love to hear it.

A: And I'd love to tell it. It's actually rather simple. The two worlds are distinct because the spheres in the worlds possess distinct properties (so the bundles of universals that are the spheres must be distinct bundles). To see this let us first assume that it is the centre of the sphere in each world that is two miles apart from itself. Now, we are agreed that the worlds are symmetrical worlds, but note that the symmetries differ in the two worlds. A plane of reflectional symmetry, for our purposes, is a plane such that any line running perpendicular through it will be such that it intersects an object with property $\mathrm{F}$ at distance $\mathrm{d}$ from the plane in one direction iff it intersects an object with property $\mathrm{F}$ at distance $\mathrm{d}$ from the plane in the other direction. In both the bi-location world and the tri-location world there is a plane of reflectional symmetry running through the centre of the bi-located sphere. But in the bi-location world there is also a plane of reflectional symmetry that runs at right angles to the plane of reflectional symmetry that runs through the centre of the sphere (i.e. at 1 mile from the sphere's centre). There is no corresponding plane of

\footnotetext{
${ }^{14}$ This is another quote from Rodriguez-Pereyra (2004, p75).
} 
reflectional symmetry in the tri-location world. However, in the tri-location world there is a plane of symmetry that runs at 60 degrees to the plane of symmetry that runs through the centre of the sphere and a plane of symmetry that runs at 120 degrees to the plane of symmetry that runs through the centre of the sphere. (Perhaps it is better to say that in the tri-location world the plane of symmetry that runs through the centre of the sphere runs at 60 degrees and 120 degrees to itself. But no matter how we put it, the point still goes through.) Are you following me?

$B$ : I think so - I'm just trying to visualise the situation...

$A$ : Perhaps if I sketch a quick diagram it will help... Here:
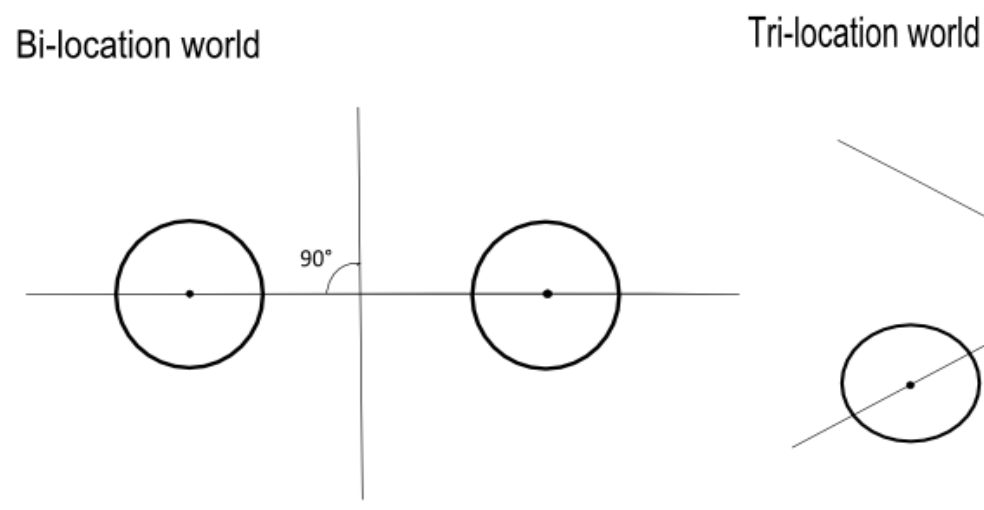

Straight lines represent lines of reflection symmetry

$A$ : This is a two-dimensional sketch but I think you can see the point. Can you see from this that, for example, in the bi-location world there is a plane of symmetry at right angles to the plane of symmetry running through the centre of the sphere, but that there is no corresponding plane of symmetry in the tri-location world.

$B$ : Yes, now I do see this clearly.

A: Good. So now you can see how I can distinguish the two worlds. I can do so simply by saying that in the bi-location world the sphere has the property of having a plane of symmetry running through it that is at right angles to a plane of symmetry, which is a property that the sphere in the tri-location world lacks. And the sphere in the tri- 
location world has the property of having a plane of symmetry running through it that is at 60 and 120 degrees to a plane of symmetry, which is a property that the sphere in the bi-location world lacks. So the worlds are distinct because the spheres in the worlds possess distinct properties (so to repeat once more, the bundles of universals that are the spheres are must be distinct bundles). So, I can distinguish between the two worlds. And so once more, then, I can recognise all of the possibilities that you can and you've done nothing at all to show that my view is false.

$B$ : All the same I am not convinced that your view is defensible.

A: Well, then, you ought to be.

\section{References}

Adams, R. M. - 1979: 'Primitive thisness and primitive identity' The Journal of Philosophy 76 (5-26)

Armstrong, D.M. - 1980: 'Against Ostrich Nominalism: a Reply to Michael Devitt' Pacific Philosophical Quarterly 61 (440-449)

Armstrong, D.M. - 1997: A World of States of Affairs (Cambridge University Press: Cambridge)

Bailey, A.M. - 2012: ‘No Bare Particulars’ Philosophical Studies 158 (1) (31-41)

Black, M. - 1952: 'The Identity of Indiscernibles’ Mind 61 (153-164)

Burke, M. B. - 1992: 'Copper Statues and Pieces of Copper: A Challenge to the Standard Account' Analysis 52 (1) (12 - 17) 
Hawthorne, J. - 1995: 'The Bundle Theory of Substances and the Identity of Indiscernibles' Analysis, Vol. 55 (pp191-196)

Kripke, S. - 1980: Naming and Necessity (Blackwell: Oxford)

Laycock, H. - 2011: 'Object' The Stanford Encyclopedia of Philosophy (Winter 2011 Edition), Edward N. Zalta (ed.)

$<$ http://plato.stanford.edu/archives/win2011/entries/object/>.

Lewis, D. - 1968: 'Counterpart Theory and Quantified Modal Logic' Journal of Philosophy 65 (5) (113-126)

Lewis, D. - 1971: 'Counterparts of Persons and Their Bodies' Journal of Philosophy 68 (7) $(203-211)$

Lewis, D. - 1986: On the Plurality of Worlds (Blackwell: Oxford)

Lewis, D. - 1991: Parts of Classes (Blackwell: Oxford)

Loux, M. - 1978: Substance and attribute (Dordrecht: D. Reidel)

Loux, M. - 2006: Metaphysics: A Contemporary Introduction (Routledge: New York)

Mackie, P. - 2008: 'Coincidence and Identity' Royal Institute of Philosophy Supplements 83 (62) (151-176)

Mertz, D. W. - 2001: 'Individuation and instance ontology' Australasian Journal of Philosophy, 79, (45-61)

Rodriguez-Pereyra, G. - 2004: 'The Bundle Theory is compatible with distinct but indiscernible particulars' Analysis 64 (72-81)

Sellars, W. - 1952: 'Particulars' Philosophy and Phenomenological Research, 13, (184-199)

Sellars, W. - 1963: Science, perception, and reality (London: Routledge \& Kegan Paul)

Simons, P. - 1994: 'Particulars in particular clothing: Three trope theories of substance' Philosophy and Phenomenological Research , 54, (553-575)

Van Cleve, J. - 1985: 'Three Versions of the Bundle Theory' Philosophical Studies 47 (1) $(95-107)$

Van Inwagen, P. - 1990: Material Beings (Cornell University Press: New York)

Wasserman, R. - 2002: 'The Standard Objection to the Standard Account' Philosophical Studies 111 (3):197 - 216.

Wasserman, R. - 2009: 'Material Constitution', The Stanford Encyclopedia of Philosophy (Spring 2009 Edition), Edward N. Zalta (ed.), 
<http://plato.stanford.edu/archives/spr2009/entries/material-constitution/>.

Zimmerman, D. - 1997: 'Distinct Indiscernibles and the Bundle Theory' Mind 106 (pp305-309) 